Journal of University of Raparin $\quad$ كوَقارى زانكوّى رايْرِين $\quad$ E-ISSN: 2522 - 7130 P-ISSN: 2410 - 1036

\title{
Complexity of Mental Representation: A Cognitive Pragmatics Perspective
}

\section{Saman Mohammad Othman}

Department of English Language, College of Education, University of Raparin, Rania, Kurdistan Region, Iraq.

E-mail: saman.en@uor.edu.krd

\section{Salah Mohammed Salih}

Department of English Laguage, Faculty of Humanities \& Social Sciences, Koya University, Koya, Kurdistan Region, Iraq.

E-mail: salah.mohammed@koyauniversity.org

\begin{abstract}
:
This article attempts to elucidate the meaning construction process, mental states and mental relations, communicative intentions, and action plans and thereby to explore the complexity of mental representations from a purely cognitive pragmatics perspective. It also attempts to reevaluate the violations of cooperative principle and maxims.

Cooperation, mental states and intentionality are the three basic tools for any communication process. Mental states are either conscious or unconscious. They are emotional and cognitive which include common attention, shared belief, and consciousness. Three different types of beliefs are differentiated: individual, common and shared. Intentionality is the relationship between mental acts and the external world. Every mental phenomenon has content and it is directed at an object. Two fundamental distinct meanings are attributed to the concept of intentionality: direction and deliberateness. Intentionality can be conceived of through communicative intentions and action plans.

The main concepts of communication, namely, cooperation, sharedness and intentionality are indispensable concepts to understand the process of comprehension and reconstruction of response in communication. Without rich shared knowledge, the inferential chain in non-standard communication becomes lengthy and laborious. Other possibilities arise due to the absence of the fundamental concepts, one of which is failure of communication. Any mental process can be envisaged in terms of steps starting with the expression of an act, moving through speaker meaning, to the communicative effect, then to the reaction it creates and finally the production of overt communicative response.

The paper examines the scale of complexity of mental representation and shows the underlying processes required in meaning construction. Additionally, the difference between standard and non-standard communication is presented in terms of complexity of inferential processes needed for each two different cases in communication.
\end{abstract}

Keywords: Mental Representations, Mental States, Intentionality, Communicative Act, Communicative Intention. 


\section{Introduction:}

While cognitive semantics explores knowledge representation and meaning construction, the major concern of cognitive pragmatics is the mental states and relatively the mental relations of the interlocutors in communication. Communication from cognitive pragmatics perspective does not negotiate meaning representation from an external observer's viewpoint as it is normative in linguistics and philosophy of language traditions where the focus is on the finished product. The cognitive outlook takes a standpoint within the mind of the individual participants endeavoring to unravel the generation of communicative acts mentally prior to their physical realization and their mental comprehension by the other partners.

The major motivation behind language study by cognitive semanticists is based on the assumption that linguistic organization, at least partially, represents the nature of conceptual system. To further substantiate the founded relationship between conceptual system and linguistic system Evans and Green (2006, p. 48) reiterate Talmy's (2000, p 4) claim that cognitive semantics is 'concerned with investigating the relationship between experience, the conceptual system and the semantic structure encoded by language.'

This article attempts to elucidate the meaning construction process, mental states and mental relations, and thus to explore the complexity of mental representations from a purely cognitive pragmatics perspective. It also attempts to reevaluate the violations of cooperative principle and maxims. In standard communication, mental states are understood via employment of default rules of inference. Default rules remain functional until explicit evidence is presented to prove it otherwise. The most important feature of standard communication is that the actor's private beliefs are in line with what he says. Comprehending a standard communicative act demands the partner to establish association between the utterance proffered by the actor and the behavior game he bids. Unlike standard communication, nonstandard communication falls beyond the boundaries of normality. Irony and deceit are cogent examples of non-standard communication; they involve the comprehension of communicative acts via blocking of default rules. They are also quite demanding because their recovery requires complex inferential processes. In the comprehension of irony and deceit, the mental representations involved in the communicative act produce incongruity between what the actor communicates and what he privately entertains.

\section{Literature review:}

Within cognitive pragmatics, Cooperation, sharedness and communicative intention are three fundamental concepts which constitute the bedrocks of the analysis of mental processes in human communication. These three fundamentals are originally proposed by Grice (1975); however, they have been subject to refinements by other scholars. The cooperative nature of human communication is evidently substantiated by evolutionary point of view and the success of communication is realized through cooperative reasoning.

The second fundamental concept is sharedness. In communication, the motivation for cooperation is not adequate alone. Interlocutors must go a step further by showing ability and willingness to share their mental states in order to fulfill the full potential of communication. However, achieving the status of sharedness does not guarantee the deliverance of the information unless the information is intentionally and explicitly suggested to the interlocutor. Communicative intention is the intention to communicate something to someone with the intention that that someone would recognize your intention for communicating that particular thing (Huang, 2017).

According to Bara (2010, p 1) cognitive pragmatics 'is the study of mental states of people who are engaged in communication.' Considering mental states for the analysis of communicative interactions involves apprising 
individual motivations, goals, beliefs and intentions. The term cognitive in cognitive pragmatics is emphasized for the fact that communication from cognitive pragmatics perspective is not investigated from a view point of an external observer as it is normative in linguistics and philosophy of language traditions where the focus is on the finished product- be it an utterance or a discourse. Whereas, the cognitive outlook takes a standpoint within the mind of the individual participants endeavoring to unravel the generation of communicative acts mentally prior to their physical realization and their mental comprehension by the other partners. In other words, the objective is to examine what happens in the mind of the participants rather than the formal structure of the message.

In cognitive pragmatics, the general term of communication is deployed to refer to the interactive process between interlocutors because it is an inclusive term that involves both linguistic and extralinguistic channels of communication. Broadening the scope of the inquiry brings along the need for richer and more encompassing terminologies. Therefore, it is preferred to replace the speaker and hearer with the terms actor and partner that refer to the participants who take active and passive roles respectively. Furthermore, during oscillating roles, both entities will be referred to as agents or interlocutors.

\section{Joint meaning construction:}

Meaning construction is a communal activity that is realized by participants in a given interaction. Bara (2010, p.15) characterizes communication as 'an activity consisting of a combined effort of actor and partner, who consciously and intentionally cooperate to construct together the meaning of their interaction.' Cognitive pragmatics theory attempts to account for both linguistics and extralinguistic aspects of interaction. Language is the major means of communication it is almost always accompanied by extralinguistic elements which provide and facilitate reciprocal comprehension. Moreover, these two modes of communication are not distinct domains but rather they are two modes of expression that complement each other. The reason for that is the fact that in certain situations extralinguistic elements can perform better than their counterpart linguistic elements in transmitting emotions and feelings. For instance, when grief is to be conveyed, the effect of embracing and weeping proves to be more forceful than words.

The two basic forms of communication are complementary but they are also significantly different in their structure. Language as an entity is based on compositionality, that is, language is made of meaning bearing constituent components; some linguistic expressions possess an atomic structure which can be subdivided into smaller units. Linguistic communication uses a system of symbols.

On the other hand, extralinguistic communication employs a set of symbols and it is associative but not compositional, in other words it consists of parts and not of constituents. It also does not possess any syntactic order. Extralinguistic signals are molecular blocks that cannot be divided any further. In other words, extralinguistic parts do not have atomic meanings into which they may be further dissected. This novel distinction between linguistic and extralinguistic forms of communication is presented by Bara (2010) due to the issue of impreciseness in the classical division between verbal and non-verbal dichotomy of communication. The old divide is based on input while the novel distinction is based on the way data are processed in the mind (Bara and Trissa 1999).

Linguistic, paralinguistic and extralinguistic aspects are constantly incorporated in normal communication which in turn modifies the nature of the interaction to achieve the desired effect. For instance, a pers on is requested to leave an office in a building using an expression with significant amount of force:

(1) You are requested to leave the premises or you shall be removed.

Instead, the same message can be delivered with neutral words, while the tone still conveys imposition: 466

DOI:https://doi.org/10.26750/Vol(8).No(3).Paper22 http://journal.uor.edu.krd/index.php/JUR Vol.8. No.3,September.2021 
(2) Please follow the instructions.

Or the words may be conveyed in a sarcastic tone, whereas the literal meaning is obviously untrue:

(3) Do whatever pleases you; I am sure it will benefit you!

In this case it is very likely that the utterance could be attended by a behavioral act that would completely manifest the real intention of the actor. Paralinguistic aspect of communication integrates both domains and determines their mode of expression. In addition to that, paralinguistic aspects of communication modify meaning and add an emotional dimension to the interaction. In speech, prosody is the most important structure of paralinguistic which consists of tone, volume, pitch, stress, speed and so forth.

\section{Communication acts:}

The pragmatic approach to language originates form the philosophy of language. In the 1930s, a movement pioneered by two philosophers, namely John Austin and Ludwig Wittgenstein led to the establishment of pragmatics. The latter was responsible for developing the theory of verificationism which had emerged from the logical positivist movement. The essence of verificationism was based on the fact that any utterance that cannot be verified based on its truthfulness was considered meaningless. The utterances that their truth value could be established were considered philosophically meaningful. For instance:

(4) a. Napoleon was a French revolutionary leader.

$b$. The French revolution abolished monarchy in France.

On the other hand, the following utterances are labeled meaningless and nonsensical taking the verificationism standards because they cannot be tested for their truth value.

(5) a. I wish I could travel the world.

b. All human beings are entitled to respect.

However, verificationism had hit a logical dead end. It posed logical problems that could not be solved. The problems were in the heart of the procedures which were used to verify the meaning of utterances. Wittgenstein (1953) suggests radical modifications to his position by introducing the concept of Language Game which is a subjective view that takes the natural, daily language use of people into account. Concurrently but independently, Austin (1962) was studying language use and had reached the same conclusions of as Wittgenstein. Speech act theory is considered the foundation of pragmatics. Austin observed that, in a given situation, certain utterances possess the same power of actions in transforming the state of the affairs. In speech act theory, the emphasis is on the success of the utterances; while truthfulness of the utterances is based on their truth value is berated and deemed as senseless. For example,

(6) I pronounce you husband and wife.

This utterance is felicitous if the utterance is produced by a licensed official in an appropriate context. Once the sentence is uttered the couple officially becomes tied to each other. Austin (1962) divides the speech act into three separate constituents: Locutionary, Illocutionary and perlocutionary acts. The first act represents the sentence meaning of the utterance with the determination of sense and reference. The second act reflects the speaker's communicative intention in uttering the message. Lastly, the perlocutionary act is the effect the speaker wishes to achieve in the mind of the interlocutor. For instance,

(7)

Locutionary act stop or you'll fall!

Illocutionary act warning to the addressee

Perlocutionary act urges the addressee to remain motionless

467

DOI:https://doi.org/10.26750/Vol(8).No(3).Paper22 http://journal.uor.edu.krd/index.php/JUR Vol.8. No.3,September.2021 
The success and failure of the three segments of speech act are governed by different sets of felicity conditions.

Furthermore, the success of the three stages is not consecutive and automatic, that is, the success of one does not guarantee the success of the next stage. For instance, example (7) the locutionary phase may fail if the addressee's hearing is impaired or does not understand English, or a loud noise overtakes the addresser's words. In case the locutionary phase was successful, this does not ascertain that the illocutionary phase achieves success because the addressee might think that the addresser is joking or mocking him. Finally, illocutionary success is not directly followed by perlocutionary success. The addressee might be fully aware of his situation and might have made up his mind about his next move. The first two stages of speech act are essentially conventional; they are associated to the area of linguistic knowledge shared by both interlocutors. Conversely, the perlocutionary act is associated with the private world of the addressee; it is realized in the mind of the addressee. Therefore, the addresser is helpless in discovering the success or failure of the perlocutionary effect (Huang, 2017).

Grice (1975) stresses the importance of cooperation between the interlocutors as a fundamental principle. The cooperative principle is divided into four categories and further into nine maxims. These maxims are not rules to be followed but they are tacitly observed to clarify the types of criteria we use to create the inferential chain. The maxims are not always followed; they are also violated for conversational purposes.

Bara (2010) presents the types of violations and divides them into two main categories, involuntary and voluntary violations. The former includes error, while the latter includes two further subparts, noncommunicative and communicative. Voluntary violations are represented by deceit and exploitation such as in (tautology, irony and metaphors).

- Error consists of an involuntary violation of a maxim. This type of violation is common in everyday conversations. The cooperative principle is not violated intentionally because the speaker does not intend to communicate something misleading. The detection of error depends on the agents' information. Sometimes errors pass unnoticed by the partner. If the speaker is in a powerful position of informationally wise, then the error escapes undetected. Otherwise, if the listener is in an informationally privileged position, the error will be recognized.

- Deceit is a violation of one or more of the maxims. It is deliberate but not communicated. The main purpose of deceit is to pull the addressee into generating incorrect inferences through deceitful communicative acts. The deceiver both consciously and intentionally attempts to deceive and mislead the addressee. Lies are the prototypical examples of deception; they come about due to violation of the quality maxim.

- Exploitation is a deliberate and open communicative violation of a maxim. The speaker urges the listener to produce a series of inferences via flouting a maxim. Exploitation is unlike deceit because the speaker signals the violation for communicative purposes while deceitful intention is kept private.

\section{Tools for communication:}

Communication requires at least two parties or actors that must have the intention to produce an act mutually. Cooperation, mental states and intentionality are the three basic tools for any communication process. 


\subsection{Cooperation:}

The full communicative nature of the act is achieved when the agents share their parts and together cooperate in the process of meaning construction. Face to face conversation is an ideal example of communication in which the interlocutors come into physical contact and share the physical co-presence. However, this privilege is not present in conversations carried out on the telephone. In telephone conversations a great deal of information is inaccessible due to absence of extralinguistic form of communication.

Therefore, the participants are obliged to rely virtually on verbal exchanges but this constraint does not abolish the validity of the communicative activity. In communication, the participants as a whole shoulder the responsibility of the successes and the failures of the conversation because it is a dynamic mode of interaction in which each agent contributes in meaning construction. The process of meaning construction is constant and all the participants actively partake in its realization.

Cooperation in communication is best received when actors entertain shared objectives. However, communication is not always flowing smoothly and nicely. In certain situations, the participants' objectives diverge and they disagree and even quarrel. Tomassello et al. (2005) reiterate and substantiate the presence of cooperation even in unfriendly exchanges between participants because there is evidence that human beings possess social capacity and cognitive skills that motivate and direct the participant's collaboration.

Grice (1989) meticulously examined the extreme cases of success and failure in his concept of cooperation. Success is realized when the speaker's wish is understood and accommodated by the partner. Failure, on the other hand, occurs when the interlocutor does not understand the Speaker's wish and intention for the speaker's desire to be detected from the partner's side is absent and therefore the conversation breaks down. However, Bara (2010) suggests that Grice had not taken 'intermediate positions' into account. Therefore, Bara subdivides cooperation into Behavioral and conversational cooperation. For example,

(8) a. It is Thursday tomorrow. Can you do the shopping?

b. of course I can.

(9) a. It is Thursday tomorrow. Can you do the shopping tomorrow?

b. I am sorry; I'll be out of town tomorrow.

In both cases, B's answers are cooperative because they are relevant to A's questions. However, it would have been completely noncooperative if B's answer were as the following:

(10) b. I feel a gentle touch of a cool breeze on my face.

(8b) is cooperative in a way that (9b) is not. (8b) accomplishes the perlocutionary effect expressed by A; that is, the answer is accompanied by the commitment of doing the shopping. It is not a mere reference to the abstract information regarding B's response. By providing a positive answer to A's question B is committing himself to deliver the act as well. According to Bara (2010) Airenti, Bara and Colombetti state that both exchanges show conversional cooperation, but only (8b) exhibits behavioral cooperation. Behavior games are a set of conversational rules which are deployed to establish behavioral and conversional games.

According to Huang (2017) Wittgenstein introduced the idea that the entire process of using words could be seen as a sort of game which he named language game. He also proposed a revolutionary thought that was one should focus on language use instead of language structure or form. Bara (2010) suggested behavior and conversational divide. It is postulated that the literal meaning of an utterance is just the starting point of its comprehension. A behavior game is defined as a structure that helps actors to coordinate their interpersonal actions. Consequently, this coordination enables actors to choose the real meaning of an utterance among a wide range of alternate meanings that particular utterance might convey. 
Operation of two actors on the behavioral level takes a plan that must be shared at least partially by the agents. Participants of a behavior game require shared knowledge to interact in a game. Moreover, playing a game includes validity conditions that specify the conditions under which the game to be conducted. The main features of validity conditions are time and place. However, some extra conditions might be needed for the games which are connected to the mental sates of the participants. Because behavior games are based on the notion of shared knowledge, each agent has his own subjective view of the game. Cognitive pragmatics deals with the global structure of dialogues based on their derivation from the shared knowledge of an action plan. Conversation game organizes the harmonious local development of the dialogue. In conversation game each participant is responsible for fulfilling a set of tasks in certain order.

\subsection{Mental states:}

According to Huang (2017) in the process of production and comprehension of communication a series of mental states are involved; these mental states which are possessed by human beings are either conscious or unconscious. They are emotional and cognitive which include common attention, shared belief, and consciousness.

1. Common attention: In communication, all participants must consciously pay attention not only to what is happening in the interaction but also be sure that every participant is paying attention too. Common attention is the most important characteristic of conversation in which participants will continually confirm and be confirmed about the reality of playing their part in interacting. Conditions of contact constitute a fundamental prerequisite for communication to mark the commencement of the game. The most significant means for establishing contact is gaze. Although, eye contact is not the only method, acoustics is a frequent alternative especially when the agents cannot visually perceive each other. After the establishment of conditions of contact, communication proceeds and the participants will have conceived that from that point on everything happens will be treated as shared knowledge.

2. Shared belief: Bara (2010, p. 70) defines belief as 'a primitive mental state'. In dealing with mental sates in communication the concept proves to be indispensable. Three different types of beliefs are differentiated as follows:

i. Individual belief: This type of belief is one dimensional, that is, it is either the individuals believe in a certain thing or believe that a certain belief is held by other agents. This type of belief happens to be autonomous and there is no connection between the agents concerning that belief.

ii. Mutual belief: It is possessed by all individuals, for example, generally, all agents share knowledge of surrounding environment or culturally transmitted knowledge. Mutual belief indicates that both A and $\mathrm{B}$ believe in $p$. therefore, both participants should hold the same mental state regarding to the belief that $p$. a certain belief such as love of football is shared between two or all the football fan base. This type of belief is spread over a wide range group of people which may be categorized based on their type of belief they have in common. Nevertheless, common belief is not sufficient to enable successful communication.

iii. Shared belief: It includes all the features of the two previous types of belief which are belief about a certain thing, share that belief with members of a group and plus the awareness from each participant that this particular belief is possessed by all those who are engaged in the speech event. Subjectivity 
is the main characteristic of shared belief. In other words, the agents cannot be sure about the possession of that particular belief by the other participants. Observation of the mental states of others in a direct way will assure you of the true knowledge of the belief to be shared.

3. Consciousness: It is the construction of awareness towards something; human mental states do not possess that feature inherently. Changing something from the state of unconsciousness to the state of consciousness must undergo certain kind of modification to attain the latter state. Alternating unconscious mental state to conscious mental state changes the knowledge content. For example, if a given thing was previously represented in a certain manner. In the transformation process it changes into a different fashion, mostly, it would take an interpretative framework

\subsection{Intentionality:}

According to Cohen, Morgan and Pollack (1990) intentionality is the relationship between mental acts and the external world; very simply set as 'aboutness'. Every physical or mental phenomenon has content and it is directed at an object. Two fundamental distinct meanings are attributed to the concept of intentionality: direction and deliberateness. Direction is an intention that is always directed at a person, an object, or event. Intentional actions and mental states are parallel with the actor's concentration on a perspective. Once the target is determined, the actor aims his action and thought towards it. Deliberateness is the second meaning of intentionality, it means that an intentional action or mental state possesses a nucleus that is 'directed, wanted, decided on, selected, pursued and so on.' However, this nucleus is not always found in all of a person's intentions because not all the results come about are based on the decisions that are made. Some outcomes are realized due to undesired consequences. Human actions have a set of consequences some of which are desirable, while others are closely tied to the premeditated goals which are inevitable and considered irrelevant and unwanted.

Intentionality can be conceived of through communicative intentions and action plans.

\section{a- Communicative intentions:}

Bara (2010, p. 82) defines communicative intention as 'the intention to communicate something, plus the intention that that intention to communicate that particular something be recognized as such.' Intentions need to be manifested and realized throughout the course of their exhibition. Since communication is a collaborative act, establishing a common ground facilitates the realization of the actor's intentions. The actor must present his intentions and embody them through communicative actions. One of the core meanings of intention is direction that is the intention of the actor is directed at a particular individual. A plan includes the process of organization of beliefs and intentions to carry out an action plan. At the core of any plan lies an intention because plans are crated through contemplation and that includes both meanings of intentionality which are deliberateness and direction. Action plans are deliberate because they are carefully set, closely studied and pursued to be achieved. In addition to that, Action plans are also directed at a person, thing or event. Therefore, intentionality is an integral part of communication and is a catalyst of action planning.

The outstanding characteristic of communicative acts that differentiates them from actions pure is that communicative acts are carried out together with someone. Communication takes place only with two agents involved in the act. There is no communication in isolation or total autonomy; it is only introspection and contemplation. In communication proper, there always must be an actor and one partner to whom the act is directed. Other agents, the audience, may fill in a role in the communication event. 
Real communication happens when the essential condition achieved through the presentation of information intentionally and explicitly to the interlocutor. The sharedness status of information alone does not mean one has communicated it. For example, by wearing my high-end new suit I show that I bought an expensive suit is shared, in this case first order intention that I bought a suit is satisfied, yet the second order intention, namely my desire to be communicate that fact to be recognized by people has not been fulfilled. It would have been satisfied have I openly said I bought a new suit. In this case, listeners would gain awareness of not only the specific fact but also of my open desire that they become aware of that. Bara (2010, p. 84) applies intentionality and consciousness to communication and proposes five types of communication acts:

\section{1- Deliberate and conscious communication acts}

Intentionality and consciousness are two fundamental properties of communication proper. Two conditions must be observed for success of communicative intentionality, first, the interlocutor must recognize the particular content of the communication (that $p$ ) and the intention to communicate that particular content must also be recognized. The second condition is of consciousness. It is not possible for the A (speaker) to possess the intention that B (partner) recognizes a certain thing without A being openly aware of his intention.

2- Intentional, nondeliberate and conscious communication acts

In this case, intentionality is missing the nucleus which is deliberateness. Nevertheless, what is being communicated is consciously executed. The speaker produces a sequence of words in an utterance or, in case of acts, a sequence of movements is generated. Throughout the process of production, the speaker is fully aware of what he is saying or doing but without prior planning of his words and acts. They are produced ad hoc to achieve a specific communicative goal. This type of communicative intention-inaction is goal directed but without deliberateness.

3- Intentional, deliberate, unconscious communication acts

This is an impossible case, because communicative intentions are always conscious. Communicating something to someone must be fully conscious.

4- Intentional, nondeliberate and unconscious communicative acts

The fourth category of the possibilities is nondeliberate, unconscious communicative intentionality. This possibility appears when we explicitly present our intentions while our behavior is incompatible with them. These unfavorable intentions are not to be recognized if they are in good terms with our primary conscious intentions. One of the most interesting types is slips of the tongue which come about due to external stimuli. For example, when a friend asks about your brother's job, while your brother is in sight, and it goes as the following:

\section{(11) a. what does your brother do?}

b. He is a butcher.

In reality, you brother is a licensed surgeon.

5- Unintentional, communicative actions and modes of being: without the intention to communicate, there is no communication. There will be only information extraction. Generally, information extraction comprises of associating meaning to the actions of others. In the case of information extraction only the observer can determine the sensible interpretation of what is perceived. 


\section{b- Action plans:}

In communication, in order to make sense of what other people try to get across, it is significant to infer their plans so as to be able to respond to their demands. According to Bara (2010, p. 89) Pollack defines plan as 'a configuration of beliefs - concerning the executability of the actions implied-and or intentions to carry out the actions referred to.' The level of plan details determines the number of steps involved in increasing the rate of explicitness and decreasing the indeterminate parts. Therefore, the greater the details, the better the level of explicitness will be. Human beings are naturally inclined towards employing ready- made plans because building plans is cognitively labor intensive and time consuming. People generally recourse to ready-made, tested templates of plans to conserve their energy and they are relatively guarantee the success of the actions. Moreover, because a structured plan is shared by members of a cultural group, it has two advantages, one of which is that the plan is easily absorbed by all the interlocutors. The second benefit is the clarity of the plan trajectory, that is, the plan has been tried before, so this provides facilitation to the members of the culture group to easily recognize the steps and the order in which the plan is executed.

Three categories of plan are outlined;

1- Individual plan: this type of plan involves only the planner, it might affect others and shape their lives in the future, but during the construction process of the plan the person does not include any one else directly. For example, when a writer produces a work, he goes single handedly but ones it is made public and published it will influence the lives of others.

2- Interpersonal plan: this type of plan reflects the nature of reciprocity of actions. Unlike individual plans, interpersonal planning involves actions that must be performed mutually by the planner and one or more partners. For instance, political leaders in the course of their decision-making other people will be both part of the action and will also be affected.

3- Shared plan: a shared plan is a type of plan that does not use ready-made templates but it depends on collaborative procedure between two people. The participants are expected to play their part in the shard action and in return they expect their partners play their part, too. A shared plan is subject to continual negotiation between agents. It does not expect a list of pre-set, default actions.

\section{Communication acts, production and comprehension:}

According to Bosco (2006) cognitive pragmatics studies different communicative phenomena within a unified theoretical framework that its theoretical analysis includes both linguistic and extralinguistic communication. The theory postulates that analyzing an utterance starts from its literal meaning; although, literal meaning is essential but not sufficient to the partner to so as to reconstruct the meaning conveyed by the actor and understand the actor's communicative intention. It is significant for the partner to recognize the 'behavior game' that is proposed to him to play by the actor. The behavior game is a social template of a behavior that is mutually shared and known by the participants of the communication interaction. The theory divides communication cases into two major types: standard and non- standard communication acts. Examples of standard communication acts include direct, conventional indirect speech acts. Comprehension of standard communicative acts with regards to mental representations, the partner has to establish a connection between the utterance presented by the actor and the behavior game. 
The communicative meaning of an utterance is an integral part of the context in which it occurs. Contextual information enables the partner to determine the nature of the behavior game rendered by the speaker. Consequently, the partner will be able to understand the communicative intention of the actor. Therefore, it is significant to bear in mind that it is the game that the utterance refers to determine the value of the utterance. A simple utterance without a game to refer to does not possess any communicative value. Bucciarelli et al. (2003) suggest two cognitive factors that impact on understanding of various categories of pragmatic phenomena:

\section{a. The inferential load:}

Searle (1969) claims that in order to understand that speech act one has to first take the literal meaning into account then the other interpretations will be derived. That is, interpreting the literal meaning of the utterance take precedence over the other derivatives. Moreover, Searle believes that understanding direct speech acts such as please open the window are easier to understand than indirect speech acts such as I wonder if you could pass the salt? because the latter require longer inferential process. Contrary to that, Quelhas and Pereira (1998) had empirically proven that both direct and conventional indirect speech acts are equally easy to understand. In another study, Bucciarelli et al. (2003) found that the difference claimed by Searle (1969) applies to nonconventional indirect speech act against direct and conventional speech acts because the former proves to be harder to understand in comparison to the latter other categories.

Cognitive pragmatics theory suggests the possibility of abandoning the distinction between direct and conventional speech acts in favor of adopting a new distinction between inferential process involved in comprehending simple and complex communicative acts. In this theory, understanding any kind of speech act by the partner relies on understanding the presented behavior game. Moreover, shard ground proves to be substantially influential in facilitating comprehension process by the interlocutor. The level of difficulty in understanding a communicative act depends on the inferential chain required to link the utterance the behavior game by the actor. In this perspective, direct and indirect speech acts are simple speech acts while nonconventional indirect speech acts are complex speech acts.

\section{b. Complexity of mental representation :}

In standard communication, mental states are understood via employment of default rules of inference. Default rules remain functional until explicit evidence is presented to prove it otherwise. The most important feature of standard communication is that the actor's private beliefs are in line with what he says. Comprehending a standard communicative act demands the partner to establish association between the utterance proffered by the actor and the behavior game he bids.

From a cognitive pragmatics perspective, the shared knowledge of action plan substantially contributes in constructing the global structure of dialogues. Behavior games not linguistic rules construct the global structure of dialogue. Both behavior games and conversation games govern the dialogue, the former is responsible for the overall process of the interaction, while the latter organizes the harmonious local development of the dialogue. The theory attempts to explain the overall plan of conversation whereas the formal rules are not accounted for. In this respect, Bara (2010, p. 131-132) suggests five stages:

Assuming that actor A produces an utterance addressed to partner; we can distinguish five logically connected steps in B's mental processes.

1- Expression of act, where A's mental state is reconstructed by B starting from the locutionary act. 
2- Speaker meaning, where B reconstructs A's communicative intentions, including the case of indirect speech.

3- Communicative effect, which consists of two processes:

(a) Attribution, where B attributes to A private mental states such as beliefs and intentions; and

(b) Adjustment, where B's mental states concerning the topic of the conversation may be altered as a result of A's utterance

4- Reaction, where B produces the intentions, he will communicate in his response

5- Response, in which B produces an overt communicative response.

The managing of the connection between these five stages is safeguarded by the conversation game. The standard order is from stage 1 to stage 5. Failure in the first three stages breaks the normal chain of the sequence and the process jumps right to the end stage. Moving to last stage due to malfunction is because in conversation game it is a rule that the partner must react to the actor's utterance even if there is no understanding; one might probably ask for clarification.

Non-standard communication, on the other hand, is also treated within the framework of cognitive pragmatics. Airenti, Bara and Colombetti (1993) suggest that standard communication can account for a wide range of linguistic phenomena including the analysis of failures, exploitations, deceitful uses and non-expressive uses of language without any special modification. Cognitive pragmatics carefully investigates the relation between behavior game and conversational aspects of dialogue. In communication, the actor attempts to leave an effect on the partner; that goal can be achieved through shaping the partners mental state or urging him to carry out an action. However, the actor's goal can be treated from two different aspects and he might achieve only of the two goals. For example, in communication one can be non-cooperative behaviorally while still willing to maintain correct conversation.

Unlike standard communication, nonstandard communication falls beyond the boundaries of normality. Irony and deceit are cogent examples of non-standard communication; they involve the comprehension of communicative acts via blocking of default rules. They are also quite demanding because their recovery requires complex inferential processes. In the comprehension of irony and deceit the mental representations involved generate incongruity between what the actor communicates and what he privately beliefs. 


\section{Conclusions:}

In cognitive pragmatics terms, intentionality, deliberateness, and consciousness constitute the backbone of the communication act process. Two cognitive factors have impact on the understanding of various categories of pragmatic phenomena: the inferential load and complexity of mental representation.

Intentionality is the relationship between mental acts and the external world. Every mental phenomenon has content and it is directed at an object. Two fundamental distinct meanings are attributed to the concept of intentionality: direction and deliberateness. Intentionality can be conceived of through communicative intentions and action plans. Action plans can be individual, interpersonal or shared.

Any mental process can be envisaged in terms of steps starting with the expression of an act, moving through speaker meaning, to the communicative effect, then to the reaction it creates and finally the production of overt communicative response.

Unlike standard communication, nonstandard communication falls beyond the boundaries of normality. Irony and deceit are cogent examples of non-standard communication; they involve the comprehension of communicative acts via blocking of default rules. They are also quite demanding because their recovery requires complex inferential processes. In the comprehension of irony and deceit the mental representations involved generate incongruity between what the actor communicates and what he privately beliefs.

Based on careful examination of the principles of communication and the tools of communication presented by cognitive pragmatics theory, it can be concluded that the main concepts of communication, namely, cooperation, sharedness and intentionality are indispensable concepts to understand the process of comprehension and reconstruction of response in communication. Cooperation is a natural human trait and it is basically inherent in every communication. Sharedness of common ground profoundly affects comprehension and response in nonstandard cases of communication. Without rich shared knowledge, the inferential chain in non-standard communication becomes lengthy and laborious. Other possibilities arise due to the absence of the fundamental concepts, one of which is failure of communication. 


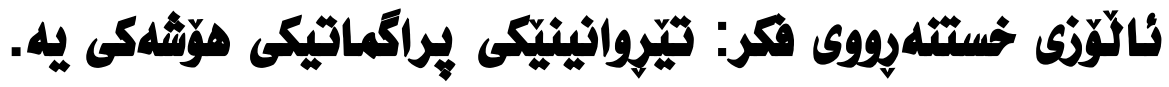

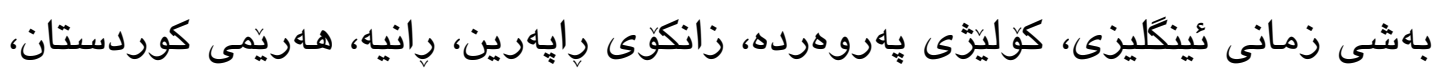

سامان محمد عثمان

عيّراق. saman.en@uor.edu.krd ئيمهيل

\section{صلاح محمل صالح}

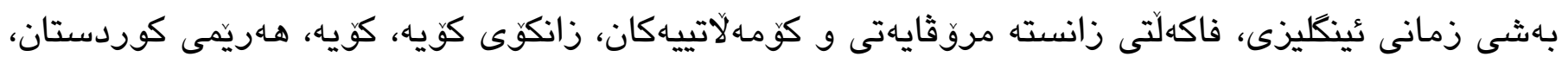
عيزراق. ئيمهيل: salah.mohammed@koyauniversity.org

צوخته

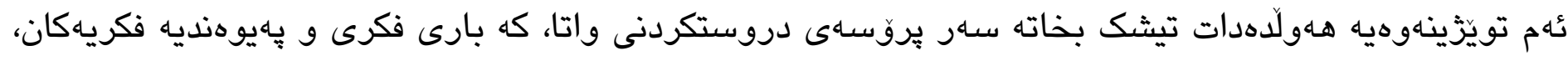

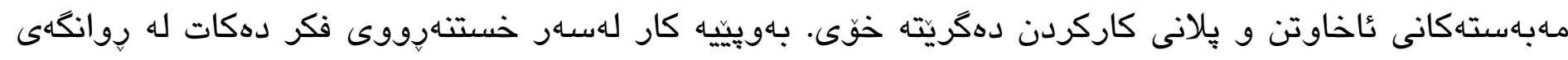

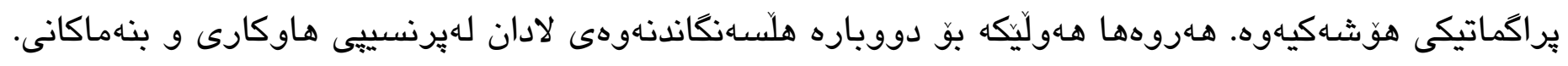

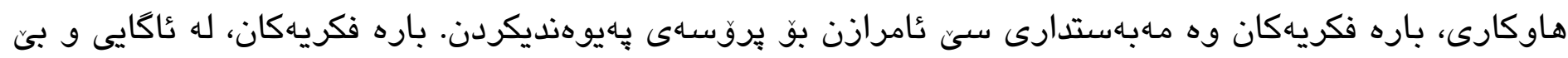

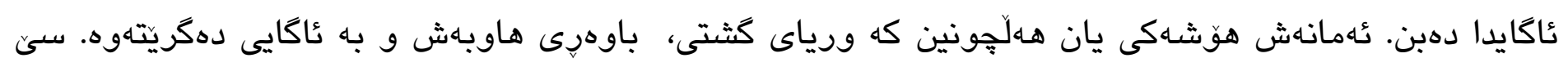

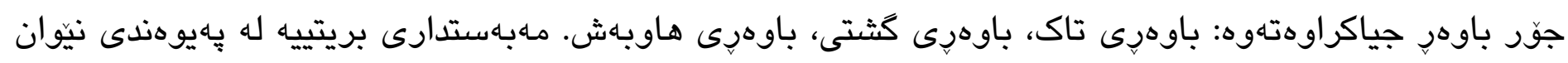

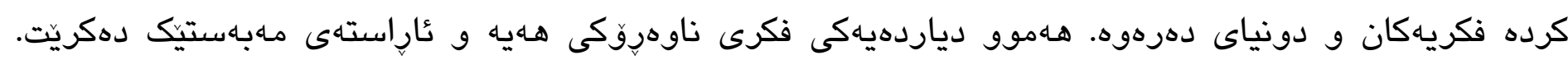

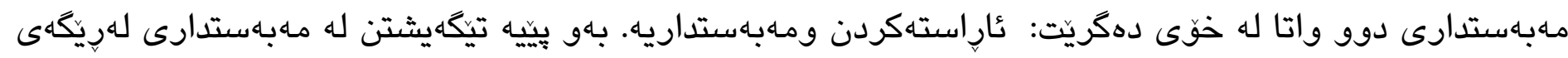

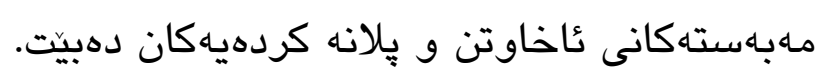

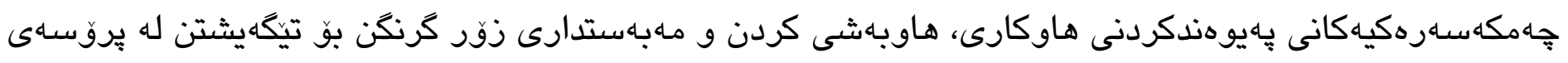

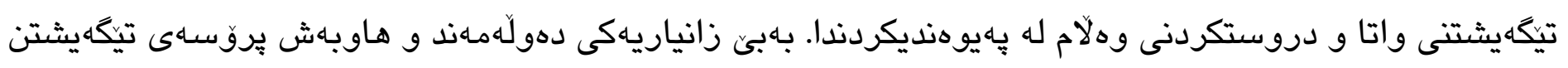

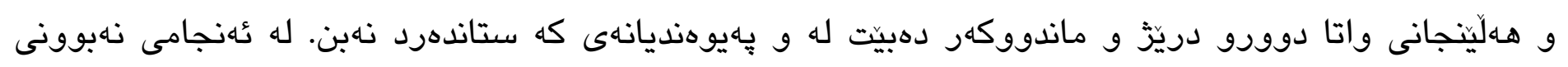

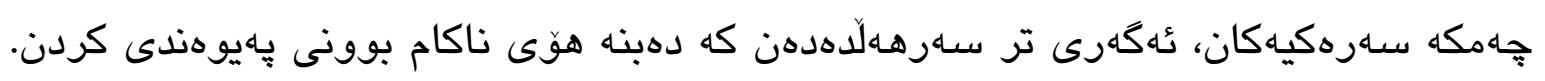


Journal of University of Raparin $\quad$ كوّقارى زانكوّى رابِّرين $\quad$ E-ISSN: 2522 - 7130 P-ISSN: 2410 - 1036

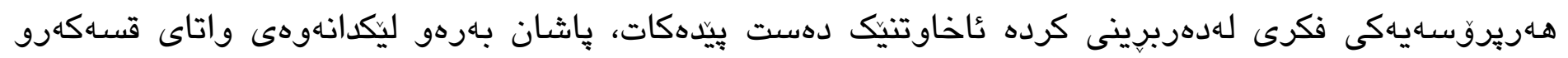

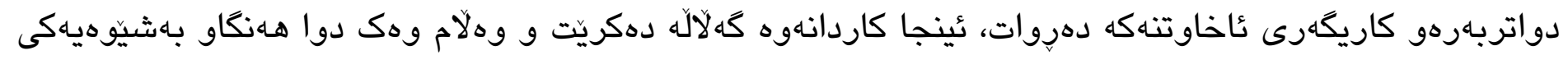

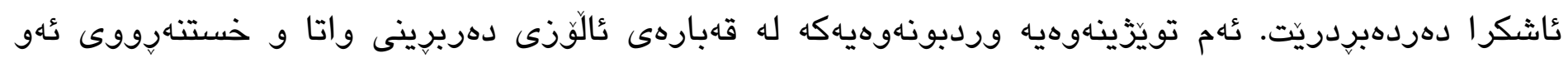

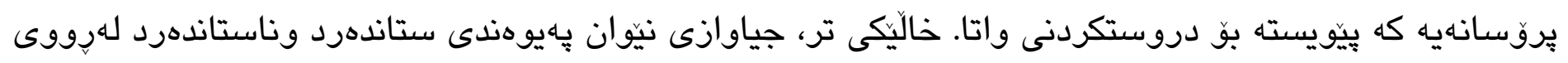

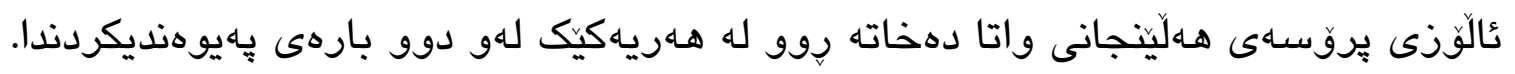

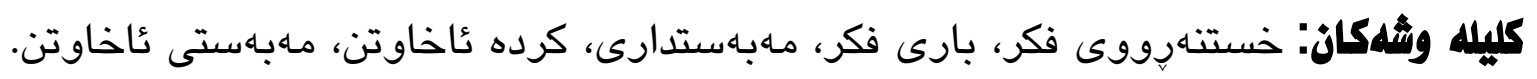




\section{References:}

Airenti, G., Bara, B. G., \& Colombetti, M. (1993). Conversation and behavior games in the pragmatics of dialogue. Cognitive Science, 17(2), 197-256. https://doi.org/10.1207/s15516709cog1702_2

Austin, J. L. (1962). How to do things with words. London, Oxford University press

Bara, B. (2010). Cognitive pragmatics: the mental processes of communication. Translated by Douthwaite, John, Cambridge (Mass.), MIT Press.

Bara, B. and Tirassa, M (1999) A mentalist framework for linguistic and extralinguistic communication. Proceedings of the $3^{\text {rd }}$ European conference on cognitive science. Roma

Bosco, F. (2006). Cognitive Pragmatics. Encyclopedia of Language \& Linguistics. 546-552. https://doi.org/10.1016/B0-08-044854-2/05038-0

Bucciarelli, M, Colle L. \& Bara, B (2003). How children comprehend speech acts and communicative gestures. Journal of pragmatics. 35(2):207-241. https://doi.org/10.1016/S0378-2166(02)00099-1

Cohen, P. R., Morgan, J., \& Pollack, M. (eds.) (1990). Intentions in Communication. MIT Press.

Evans, V., \& Green, M. (2006). Cognitive linguistics: An introduction. Edinburgh, Edinburgh university press.

Grice, H. P. (1989). Studies in the way of words. Cambridge: Harvard University Press.

Grice, H. P. 1975. Logic and Conversation. In Syntax and Semantics, Leiden, The Netherlands: Brill. https://doi.org/10.1163/9789004368811_003

Huang, Y(ed.). (2017). The oxford handbook of pragmatics. Oxford: Oxford university press.

Quelhas F.C. \& Pereira F. (eds.) (1998). Cognition and context. Lisbon. Instituto Superior de Psicologia Aplicada.

Searle, J. (1968) Speech acts: an essay in the philosophy of language. Cambridge. Cambridge university press. Talmy, L. (2000). Toward a cognitive semantic: Typology and process in concept structuring. Cambridge: MIT Press.

Tomasello, M., Carpenter, M., Call, J., Behne, T. and Moll, H. (2005). Understanding and sharing intentions: The origins of cultural cognition. Behavioral and brain sciences, 28(5), 675-691.

DOI: $\underline{10.1017 / S 0140525 X 05000129}$

Wittgenstein, L. (1953). The philosophical investigations. Oxford: Blackwell. 